\title{
Sensoriamento Remoto aplicado à análise da regeneração da vegetação natural do Parque Estadual da Lapa Grande, Montes Claros, Minas Gerais
}

\section{Remote Sensing applied to the analysis of the regeneration of natural vegetation of the Lapa Grande State Park, Montes Claros, Minas Gerais}

\begin{abstract}
Renato Ferreira da Silva Mestrando em Geologia, Universidade Federal dos Vales do Jequitinhonha e Mucuri, Brasil ferreiradasilva@yahoo.com.br

Matheus Simões Santos Doutorando em Geociências (Geoquímica), Universidade Federal Fluminense, Brasil matheusanalytica@gmail.com

Francyelle Durães Santana Graduada em Geografia pela UNIMONTES, Brasil francyalkmim@yahoo.com.br

Yasmine Simões de Oliveira Mestranda em Engenharia Civil - Universidade Federal de Uberlândia, Brasil yasmine.oliveira@ufv.br

Bruno Teles de Souza Mestre em Geologia, Universidade Federal dos Vales do Jequitinhonha e Mucuri, Brasil brteles@hotmail.com
\end{abstract}

\begin{abstract}
Resumo
O Parque Estadual da Lapa Grande localizado no município de Montes Claros, norte do Estado de Minas Gerais, foi criado por meio do Decreto Estadual N. ${ }^{0} 44.204$ de 10 de janeiro de 2006. O Parque Estadual da Lapa Grande possui área aproximada de 9.600,00 ha, seu objetivo é a manutenção dos ecossistemas sem as alterações causadas por interferência humana, admitindo apenas o uso indireto dos seus atributos naturais. Este trabalho tem como objetivo analisar a regeneração da vegetação natural sobre áreas de uso antrópico após a criação da Unidade de Conservação (UC), entre os anos de 2006 e 2017, por meio do uso de produtos orbitais e técnicas de sensoriamento remoto como ferramenta imprescindível para a mensuração de dados, foram realizadas classificações supervisionadas da área de estudo. Com isso foi possível analisar o avanço da regeneração e identificar as principais áreas antropizadas. Para a execução deste trabalho foram utilizadas imagens do satélite sino-brasileiro CBERS2 câmera CCD e CBERS4 câmera MUX, ambas imagens geradas possuem a mesma resolução espacial de $20 \mathrm{~m}$ e o mesmo comprimento de onda para as bandas $2,3 \mathrm{e}$ 4. Por fim foram gerados mapas temáticos, relacionados ao uso do solo no Parque Estadual da Lapa Grande, e gráficos que auxiliaram a análise do cenário vigente. Identificou-se uma redução nas áreas totais de cerrado stricto sensu, em contrapartida, houve um aumento nas áreas antropizadas de solo exposto proveniente da reincidência de incêndios na UC. Verificou-se ainda, um aumento significativo nas áreas de Florestas Estacionais e uma redução nas áreas que se apresentaram enquanto áreas em regeneração.
\end{abstract}

Palavras-chave: Unidade de Conservação; Ecossistemas; Sensoriamento Remoto; Regeneração da Vegetação. 


\begin{abstract}
The Lapa Grande State Park, located in the municipality of Montes Claros, in the north of the State of Minas Gerais, was created through State Decree N ${ }^{\circ}$. 44,204 of January 10, 2006. The Lapa Grande State Park has an area of approximately $9,600.00$ ha. Its objective is to maintain ecosystems without the changes caused by human interference, admitting only the indirect use of its natural attributes. This work aims to analyse the regeneration of natural vegetation on areas of anthropic use after the creation of the Conservation Unit, between the years 2006 and 2017, through the use of orbital products and remote sensing techniques as an indispensable tool for data measurement, supervised classifications of the study area were performed. With this, it was possible to analyse the progress of regeneration and identify the main anthropised areas. The execution of this work used images of the Sino-Brazilian satellite CBERS2 CCD camera and CBERS4 MUX camera. Both images generated have the same spatial resolution of $20 \mathrm{~m}$ and the same wavelength for bands 2, 3 and 4 . Finally, thematic maps were generated related to land use in the Lapa Grande State Park, and graphs helped analyse the current scenario. A reduction was identified in the total areas of Cerrado stricto sensu; on the other hand, there was an increase in the anthropic areas of exposed soil from the recurrence of fires in the CU. There was also a significant increase in Seasonal Forests and a reduction in the areas that presented themselves as areas in regeneration.
\end{abstract}

Keywords: Conservation Unit; Ecosystems; Remote Sensing; Vegetation Regeneration.

\title{
1. INTRODUÇÃO
}

Parque Estadual da Lapa Grande é uma área de preservação ambiental prioritária, devido ao fato de apresentar feições geomorfológicas típicas de regiões cársticas como cavernas, dolinas, sumidouros e ressurgências. Os aspectos vegetais do Parque Estadual da Lapa Grande são caracterizados pelas fitofisionomias do Bioma Cerrado, como Floresta Estacional Decidual, localizadas nas vertentes da bacia hidrográfica e nos topos de morro e do Cerrado Stricto Sensu, localizado prioritariamente em áreas de relevo mais suave, como as chapadas, já nos fundos de vale, há predominância de mata ciliar.

O sensoriamento remoto é uma ferramenta extremamente importante para analisar e mapear o uso de cobertura do solo, pois permite uma aquisição de dados de forma global, rápida e confiável (ROSA, 2003). Atualmente, o sensoriamento remoto é amplamente aplicado no monitoramento de coberturas vegetais, principalmente no comportamento espacial e/ou fisiológico da vegetação (ABREU; COUTINHO, 2014). O uso de tal ferramenta para basear estudos de caráter ambiental em áreas remotas e extensas como as Unidades de Conservação, é de fundamental importância, pois permite que sejam realizadas análises comparativas a partir das classificações de uso do solo e da geração, por exemplo, de índices relacionados a vegetação (ABREU; COUTINHO, 2014).

Desta forma, realizar avaliações acerca das condições ambientais de áreas florestais perpassa quase que necessariamente pelo uso de produtos orbitais pelo fato desses possuírem uma vasta lista de sensores e características espectrais diferentes, o que possibilita a execução de estudos com objetivos variados, disponibilizando dados de determinadas áreas ao longo de uma série histórica, de maneira contínua (ROSA, 2003; SANTIAGO; PEREIRA, 2009; NERY, 2014). 
O Cerrado é responsável por 5\% da biodiversidade do planeta, é uma das savanas mais ricas do mundo, ocupando uma área de aproximadamente dois milhões de $\mathrm{km}^{2}$ no território brasileiro e que originalmente cobria $22 \%$ do território de forma contínua por 10 Unidades da Federação: São Paulo, Paraná, Mato Grosso do Sul, Minas Gerais, Goiás, Mato Grosso, Bahia, Tocantins, Piauí e Maranhão além do Distrito Federal, fato esse que lhe garante o patamar de segundo maior bioma no território brasileiro ficando atrás, apenas, da floresta amazônica (RATTER; RIBEIRO, 1996; RIBEIRO; WALTER, 1998).

Segundo o Ministério de Meio Ambiente - MMA (2002) o Cerrado é um hotspot acompanhado da Mata Atlântica, devido ao fato de serem ricos em biodiversidade e severamente ameaçados principalmente por fatores antrópicos.

O limiar entre o estágio de degradação ou perturbação ambiental se dá com base na capacidade de recuperação do próprio ambiente, caso o ambiente não consiga se recuperar, este será definido como degradado (antropizado) e necessita de intervenções, em contrapartida, se a capacidade de regeneração for mantida, este ambiente será definido como perturbado e intervenções poderão acelerar o processo de recuperação (CORRÊA; MELO, 1998).

Dentro desse contexto, a abordagem do trabalho se objetiva na análise das áreas antropizadas no período compreendido entre os anos de 2006 e 2017, por meio do uso do sensoriamento remoto, como técnica para se obter dados acerca do uso e ocupação do solo da UC e consequentemente se obter dados referentes a evolução ou regressão das áreas antropizadas. Com o advento das geotecnologias, obter dados acerca de áreas remotas e de grandes extensões geográficas com o uso de imagens de satélites, tornou-se algo imprescindível para a realização de trabalhos de avaliação e monitoramento ambiental.

A escolha do tema em questão, se dá pela importância da UC no contexto regional, uma vez que está localizada aproximadamente a $8 \mathrm{~km}$ de distância do centro do município de Montes Claros MG, apresentando em sua zona de amortecimento, conflitos no tocante ao avanço de chacreamentos irregulares e em suas adjacências, mineração de calcário. Com isso a UC tem um grande desafio, que é reduzir suas áreas antropizadas para que haja uma contrapartida quanto a questão ambiental local.

\section{MATERIAIS E MÉTODOS}

\subsection{Localização}

O Parque Estadual da Lapa Grande está localizado no município de Montes Claros no Norte do estado de Minas Gerais, entre as coordenadas $16^{\circ} 43^{\prime} 00^{\prime}$ de latitude e $43^{\circ} 57^{\prime} 00^{\prime \prime}$ de longitude, a cerca de 8 quilômetros do centro urbano deste município (VELOSO; NERY, 2011) como mostra a Figura 1. 
O Parque Estadual da Lapa Grande (PELG) foi criado pelo Decreto Estadual N. ${ }^{\circ} 44.204$ de 10 de janeiro de 2006, com área aproximada de 9.600,00 ha (nove mil e seiscentos hectares). Enquanto Unidade de Conservação de Proteção integral teve sua área ampliada pelo decreto 46.692 de 29 de dezembro de 2014 para 15.360,00 ha (quinze mil e trezentos e sessenta hectares). A área apresenta o Cerrado enquanto Bioma dominante, juntamente de fitofisionomias, sendo elas a Floresta Estacional Decidual e Semidecidual além de Mata Atlântica (BARBOSA et al., 2015).

A Unidade de Conservação em estudo trata-se de um importante fragmento florestal por ser considerado primordial para manutenção ambiental principalmente das áreas de recarga hídrica (as chapadas e cabeceiras de drenagem) das bacias hidrográficas dos rios Lapa Grande e do Cedro, que são afluentes da margem esquerda do rio Vieira, principal canal de drenagem da cidade de Montes Claros-MG.

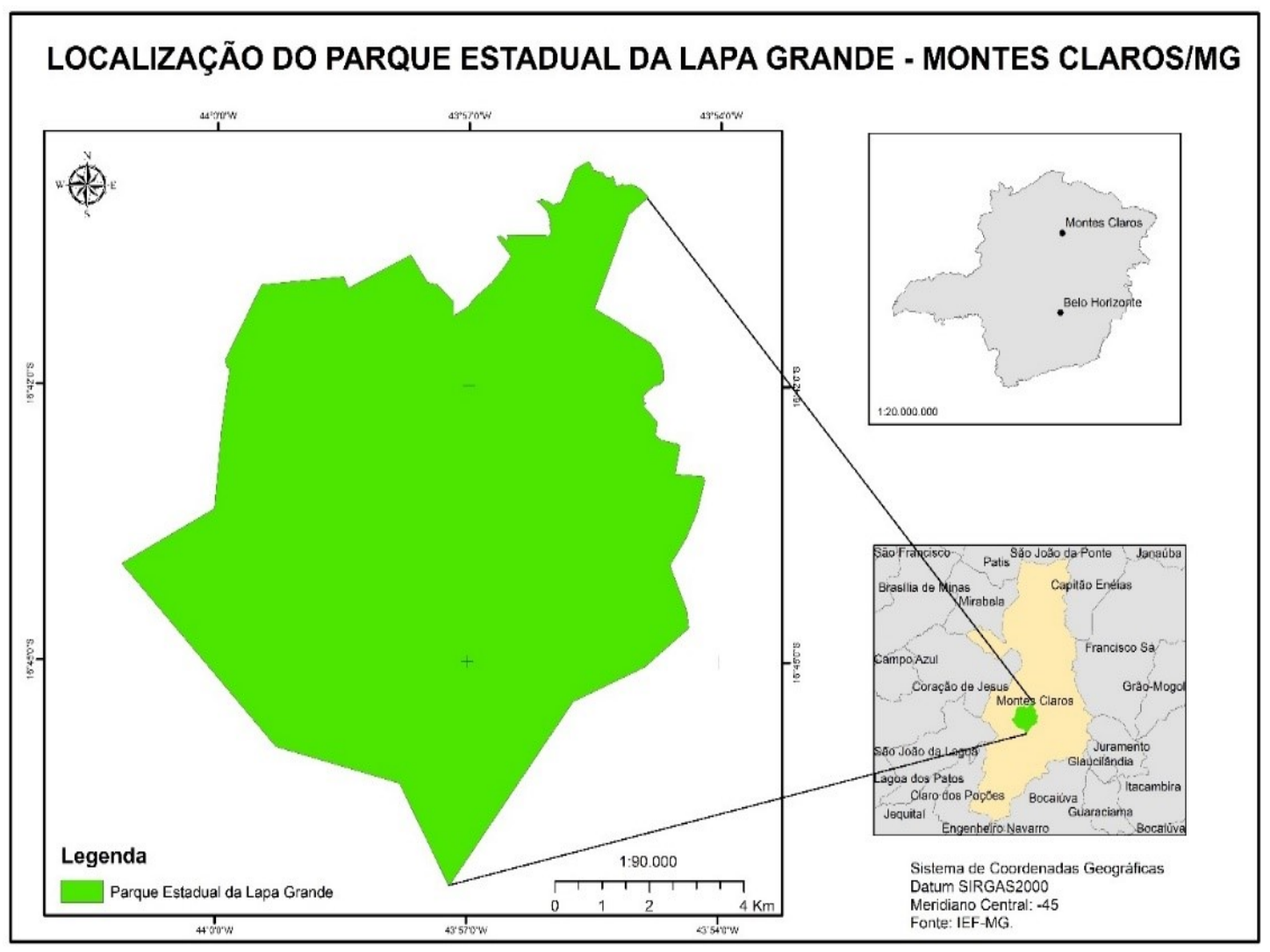

Figura 1 - Mapa de Localização do Parque Estadual da Lapa Grande.

Fonte: Renato Ferreira, 2019.

\subsection{Caracterização Fisiográfica}

O clima da região é classificado como tropical quente semiúmido úmido, próximo aos limites do semiúmido seco, com períodos de 4 a 6 meses secos. Como o clima é quente e seco e as temperaturas são elevadas durante quase todo o ano, caracterizado por elevada insolação e baixa umidade relativa do ar nas áreas de maior incidência de radiação solar, ocorrem os valores máximos de evapotranspiração, que estão quase sempre acima dos níveis de precipitações. Além de possuir 
manchas de cerrado e mata seca como formas vegetacionais (CARNEIRO, 2003; VELOSO; NERY, 2011).

No contexto geológico, a região situa-se na porção sul do Cráton do São Francisco, limitado pelas faixas de dobramento brasilianas, estabelecidas entre 450 e $680 \mathrm{Ma}$, Brasília a sul e a oeste; Rio Preto a noroeste; Riacho do Pontal e Sergipana a norte e Araçuaí a sudeste, identificando sedimento proterozoico das unidades do Supergrupo Espinhaço e do Grupo São Francisco. No último, todas as sequências deposicionais do Proterozoico Superior estão localizados como os do Grupo Macaúbas e do Grupo Bambuí-Formação Lagoão do Jacaré (ALKMIN; MARTINS-NETO, 2001).

A região está inserida na Depressão do São Francisco, que possui planícies deposicionais. Entre essas superfícies erodidas, pode-se ver o resultado da erosão diferencial sobre as rochas carbonáticas do Grupo Bambuí-Formação Lagoão do Jacaré (TRAVASSOS; OLIVEIRA, 2016).

Do ponto de vista geomorfológico a região está localizada em uma área que prevalece o relevo cárstico desenvolvidos em rochas carbonáticas (calcário) do Grupo Bambuí-Formação Lagoa do Jacaré. O cartes tem como característica um relevo acidentado e ruiniforme apresentando feições características peculiares dessa morfologia, tais como, cavernas, dolinas, uvalas, maciços fissurados, lapiás, torres, vales, sumidouros, ressurgências dentre outros. (PILÓ, 1997; TRAVASSOS; KOHLER 2009)

As rochas carbonáticas dissolvem-se naturalmente pela ação da água acidulada, dando origem aos espeleotemas (estalactites, estalagmites, travertinos, bolhas de calcita dentre outros). As cavernas, parte importante desse sistema paisagístico maior, são testemunhos dessa ação erosiva ao longo de milhares de anos (TRAVASSOS; KOHLER 2009).

A rede hidrográfica é marcada pela presença de sumidouros e ressurgências típicas de áreas cársticas, destaca-se ainda que a bacia do córrego dos bois é marcada pela presença de duas subbacias, a do rio Lapa Grande e do córrego São Marcos, que perfazem a área do PELG (MIRANDA, 2008). A bacia do córrego dos Bois é a principal dentro da UC uma vez que contribui diretamente para o abastecimento de água na cidade de Montes Claros-MG sendo responsável por 30\% de fornecimento de água, atendendo a região oeste da cidade (MIRANDA, 2008).

O Parque Estadual da Lapa Grande está inserido no bioma Cerrado, sua vegetação é marcada pela transição entre Cerrado e Floresta Estacional Decidual (mata seca), além de possuir trechos de Floresta Estacional Semidecidual associados aos cursos hídricos. A transição se faz da região da chapada de ocorrência de cerrado, onde predomina a fitofisionomia de cerrado strictu sensu, para o vale que propicia o desenvolvimento de Floresta Estacional Semidecidual nas encostas e margens dos rios e Floresta Estacional Decidual (mata seca) associada aos afloramentos rochosos (HOFFMANN, 2013). Na porção a montante tem-se cerrado típico bem antropizado marcado com pastagem e nos fundos de vales tem-se matas ciliares (MIRANDA, 2008). 


\subsection{Metodologia Proposta}

Foram utilizados os softwares ArcGIS 10.2 licenciado pelo laboratório de Geoprocessamento da Universidade Estadual de Montes Claros (Unimontes); juntamente ao software SPRING 5.1, além de arquivos em shapefile de órgãos como Instituto Estadual de Floresta (IEF), para a criação de mapas temáticos.

Também foram utilizados, enquanto materiais bases vetoriais georreferenciados referente ao limite e hidrografia da área do Parque Estadual da Lapa Grande disponível no site do Zoneamento Ecológico Econômico de Minas Gerais (ZEE); os perímetros da bacia do Rio Viera e da área urbana de Montes Claros - MG disponibilizados pelo laboratório de Geoprocessamento da Unimontes, todos esses arquivos foram necessários para a criação de mapas temáticos.

A primeira etapa do trabalho constituiu-se da pesquisa bibliográfica de obras que abordam: a regeneração vegetal; o ambiente cárstico e sensoriamento remoto. Em seguida, as imagens de satélites foram adquiridas gratuitamente através do catálogo de imagens no site do Instituto Nacional de Pesquisa Espacial (INPE) imagens do satélite CBERS2 câmera CCD com 20 metros de resolução espacial de 06 de Abril de 2006 (ano que a UC estudada foi criada) órbita e ponto 153/119 e CBERS4 câmera MUX também com 20 metros de resolução espacial de 07 de Maio do ano de 2017 da mesma órbita e ponto, isso se deve ao fato do trabalho de campo para coleta de pontos com GPS referentes a vegetação, pastagem e solo exposto ter se realizado em Julho de 2017.

Optou-se pelas respectivas por considerar-se o encerramento do período chuvoso na região de estudo, fazendo com que praticamente não haja interferência de nebulosidade característica do período úmido nas imagens.

Este trabalho levou em consideração apenas o perímetro definido pelo decreto 44.204 de 2006 para a realização das análises comparativas das áreas que foram regeneradas entre os anos de 2006 e 2017, sendo assim, não foram abordados os dados referentes a área de ampliação da UC, que ocorreu no ano de 2014, uma vez que a área que foi ampliada não fazia parte do perímetro instituído na data da criação da UC.

Após a aquisição das imagens, foi realizada a composição colorida RGB no software SPRING 5.3 sendo utilizadas as bandas 2 (verde), 3 (vermelho) e 4 (infravermelho próximo) tanto do CBERS2 quanto do CBERS4, baseando-se nos resultados satisfatórios para a classificação supervisionada em área de Cerrado, conforme-os trabalhos realizados, para monitoramento, por Brito e Prudente (2005), Santiago e Pereira (2009), Stefanes e Filho (2009) e Nery (2014).

Finalizada a composição colorida, se fez necessária a realização de correção geométrica, uma vez que a imagem referente ao ano de 2006 apresentou um deslocamento real em relação a área estudada. 
Foram utilizados como base para o registro da imagem CBERS-2, uma imagem Quickbird da cidade de Montes Claros-MG e uma imagem do Google obtida através do software Terra Incógnita, referente a área do Parque Estadual da Lapa Grande, além da base vetorial da hidrografia da bacia do Rio Vieira e a realização de visita in loco para aquisição dos pontos de controle. Posteriormente ao registro a cena foi recortada utilizando o arquivo shapefile do limite do Parque Estadual da Lapa Grande, a fim de otimizar o processamento de dados. Tal procedimento foi realizado no software ArcGis 10.2 através dos comandos Spatial Analyst Tools $\rightarrow$ Extraction $\rightarrow$ Extract by Mask.

Na sequência, as imagens foram classificadas no software Spring 5.1 utilizando a técnica de classificação supervisionada e o classificador MAXVER.

Para classificar a imagem, foram escolhidas as classes de uso do solo, como: cerrado stricto sensu; área de cerrado em regeneração, Floresta Estacional Decidual (FED), e áreas antropizadas (pastagem e solo exposto). A definição das classes enquanto áreas de treinamento, foi baseada na resposta espectral dos alvos e no conhecimento prévio da área a ser classificada. Foram obtidas, durante o procedimento de treinamento, aproximadamente 40 amostras para cada classe dentro do perímetro do Parque Estadual da Lapa Grande.

Realizada a classificação dos dados, foi feito o cálculo da área de cada classe de uso do solo em hectares no software ArcGis 10.2 usando os comandos open attribute table $\rightarrow$ add field $\rightarrow$ Calculate Geometry, estes foram tabulados em gráficos comparativos no software Excel, apresentando cada classe de uso do solo e suas respectivas áreas relacionadas aos anos de 2006 e 2017, o que possibilitou a análise da dinâmica de uso do solo.

Finalizando os procedimentos metodológicos, foram elaborados os mapas temáticos de uso e ocupação do solo do Parque Estadual do Lapa Grande no software ArcGIS 10.2 por meio da conversão de dados matriciais, obtidos na classificação, em dados vetoriais, o que possibilitou a manipulação dos arquivos na parte de Layout View, facilitando a leitura, a apresentação dos dados comparativos e análise da dinâmica da regeneração das áreas antropizadas dentro da UC.

\section{RESULTADOS E DISCUSSÃO}

Para a melhor compreensão do cenário analisado, se fez necessário visualizar quais eram as situações nos anos de 2006 e 2017, no tocante ao uso e ocupação do solo, por isso foi imprescindível a apresentação de uma carta imagem que evidenciasse ambas as situações.

A seguir, a Figura 2 expõe a carta imagem com a composição colorida (RGB) da UC nos respectivos anos que foram definidos para análise da regeneração de áreas antropizadas. 


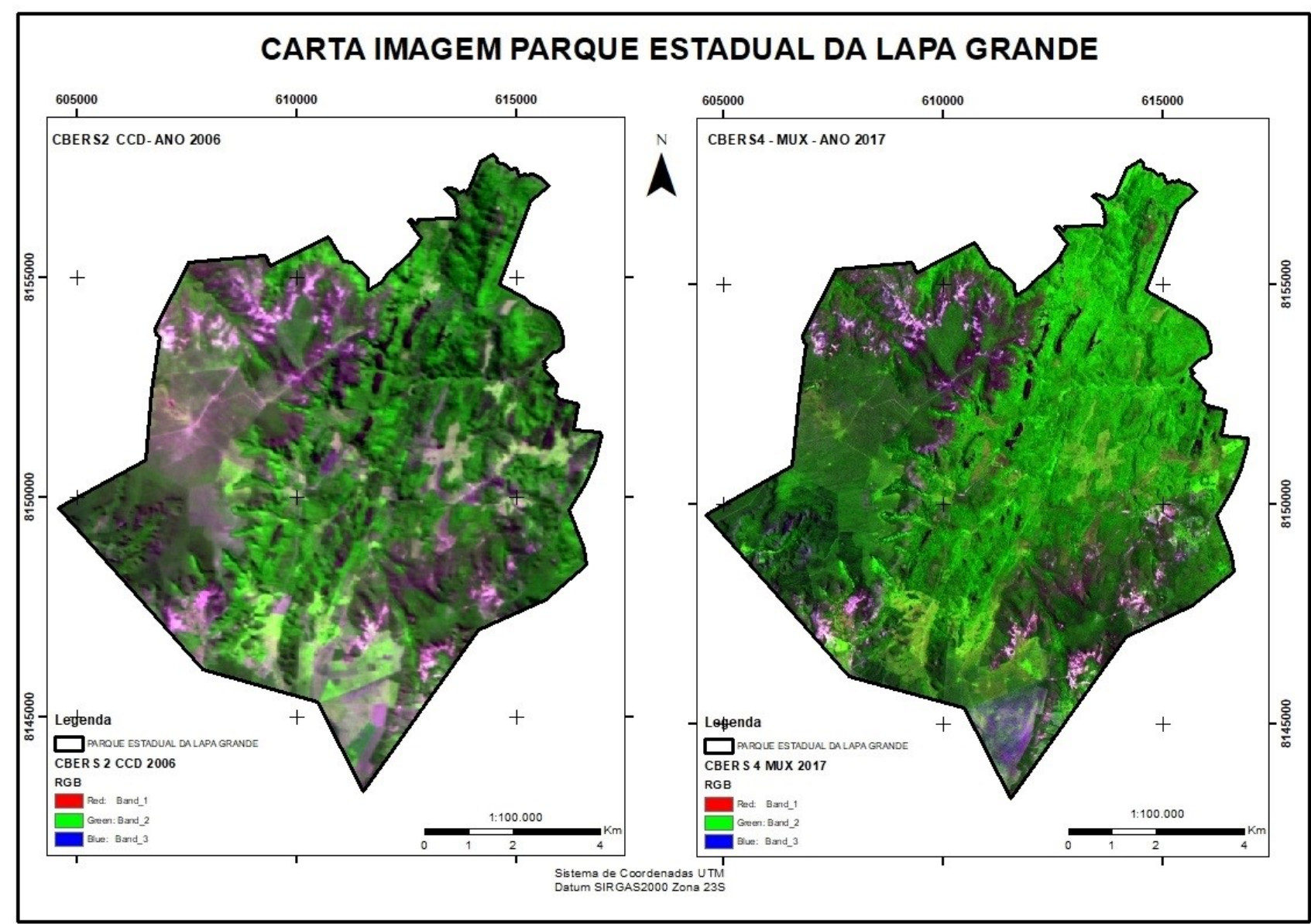

Figura 2 - Comparação entre imagens do Parque da Lapa Grande nos anos de 2006 e 2017.

Fonte: Renato Ferreira, 2019.

As classificações supervisionadas da área de estudo através das imagens CBERS2 e CBERS4 permitiram analisar qual era o cenário em relação ao uso e ocupação do solo dentro da UC no ano que foi criada em 2006 e comparar com dados gerados referentes ao ano de 2017.

Nota-se que, houve redução significativa de áreas em recuperação principalmente na porção oeste da UC onde estão localizadas as principais cabeceiras de drenagem da bacia do rio Lapa Grande. Essas áreas foram identificadas na imagem do ano de 2006 com a cor magenta, sobreposta com o verde em tom claro com pouca intensidade. O relevo nesta região é plano, característico das chapadas no Cerrado, essa área sofria com intensa antropização e apresentava, no ano de 2006, vegetação em estágio primário, já no ano de 2017 , verificou-se que a vegetação apresentava características de Cerrado Stricto Sensu, o que pode ser verificado por meio da alta reflectância do verde em tom escuro em quase toda porção oeste da UC.

As áreas de chapadas foram utilizadas historicamente por atividades agropecuárias que proporcionaram a ocupação da região. Áreas em recuperação apresentaram um valor total de 1627,38 ha no ano de 2006 já no ano de 2017 o valor foi de 1095,38 há, o que representou uma redução de 532 ha o que equivale à $32,69 \%$ desta classe. O processo de regeneração foi significativo nessa região devido ao fim da execução das atividades agrícolas por força da criação do parque, fato que colaborou 
para um cenário favorável ao crescimento e desenvolvimento do cerrado stricto sensu, tendo a gestão da UC atuado de maneira incisiva por meio do plantio direto de mudas.

Com o fim das atividades de agropecuária, iniciou-se o processo de regeneração natural das fitofisionomias do Cerrado, as matas ciliares apresentaram bom estado de preservação e recuperação, bem como a Floresta Estacional Decidual (FED). O fato de estarem localizadas nos fundos de vales e nas vertentes próximas aos principais cursos d'água respectivamente, a preservação das matas ciliares foi primordial para ascensão dessa classe vegetal.

A Floresta Estacional Decidual - FED como citado acima obteve ganho de 761,28 ha em sua área total, passando de 2375,38 ha em 2006 para 3136,66 ha, valor que representou aumento de 32,04\%. Já as áreas de Cerrado Stricto Sensu, sofreram, no período estudado redução de 4302,67 há para 3610,92 há, o que representou uma perda de 691,75 ha e um total de 16,07\% entre 2006 e 2017, essa redução pode ser explicada principalmente pelo fato da UC ter sofrido nos últimos anos, queimadas frequentes de grande magnitude fazendo com que a classe de solo exposto tenha sofrido ganho significativo. A seguir. a Figura 3 apresenta as classificações realizadas, permitindo a análise da dinâmica da regeneração das áreas antropizadas.

As áreas antropizadas foram definidas neste trabalho, como sendo as classes de pastagem e solo exposto, esta última classe apresentou, em 2006, área total no valor de 451,07 ha e no ano de 2017 valor de 1007,26 ha o que resultou em um aumento de 556,19 ha equivalentes a 123,30\% conforme apresentado na Erro! Fonte de referência não encontrada..

Há que se registrar a dificuldade, por parte do órgão gestor da área, no tocante a recuperação de áreas de solo exposto e pastagem, que todo o manejo de áreas antropizadas está vinculado ao desenvolvimento de atividades de caráter manual e é vedado o uso de qualquer defensivo agrícola para evitar o crescimento do pasto.

Nesse cenário, o pasto dificulta o processo de regeneração da vegetação em estágio primário de sucessão ecológica, a UC por sua vez, atua com plantio direto de mudas nativas desenvolvidas em seu próprio viveiro florestal, contudo, a administração passa por problemas de diversas ordens, desde técnicos (faltam profissionais com experiência em recuperação de áreas) até financeiros e operacionais, como a redução de frota de veículos, o que se torna um gargalo a ser superado. 


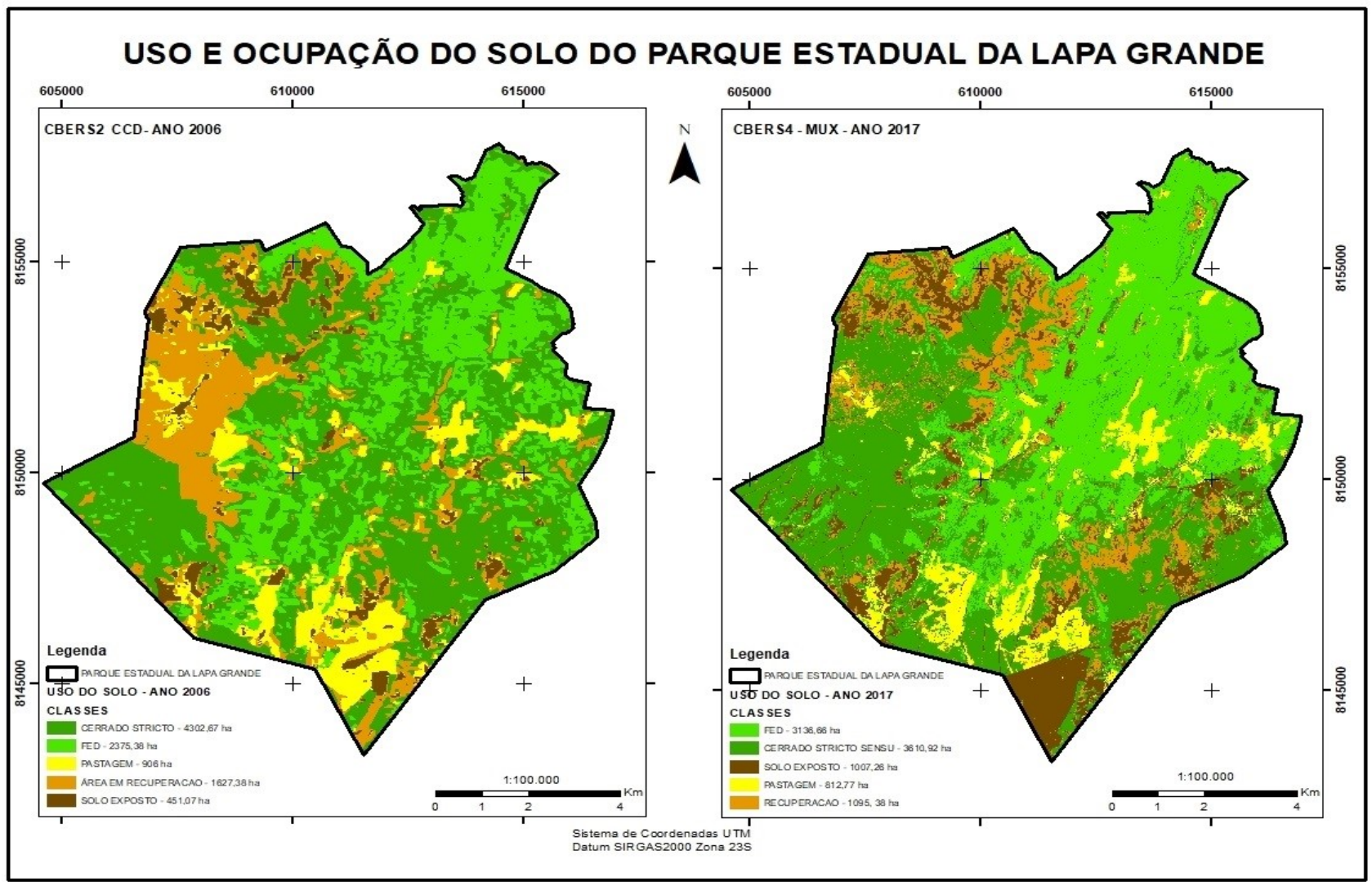

Figura 3 - Mapa de Uso e Ocupação do solo no Parque Estadual da Lapa Grande nos anos de 2006 e 2017.

Fonte: Renato Ferreira, 2019.

Tabela 1: Áreas das classes de uso do solo no Parques Estadual da Lapa Grande.

\begin{tabular}{lcc}
\hline \multicolumn{3}{c}{ Áreas Uso do Solo } \\
\hline \multicolumn{1}{c}{ Classes } & $\mathbf{2 0 0 6}$ & $\mathbf{2 0 1 7}$ \\
\hline CERRADO STRICTO & & \\
SENSU & 4302,67 & 3610,92 \\
FED & 2375,38 & 3136,66 \\
PASTAGEM & 906 & 812,28 \\
RECUPERAÇÃO & 1627,38 & 1095,38 \\
SOLO EXPOSTO & 451,07 & 1007,26 \\
TOTAL & $\mathbf{9 6 6 2 , 5}$ & $\mathbf{9 6 6 2 , 5}$ \\
\hline
\end{tabular}

Fonte: Renato Ferreira, 2019.

Por fim, a classe de pastagem apresentou uma queda de 93,72 ha no período entre 2006 e 2017, passando de 906 ha para 812,28 há, o que corresponde a 10,34\%. A pastagem, talvez seja, a classe com maior dificuldade para a gestão da UC, uma vez que se desenvolve em um ritmo maior que a vegetação em processo de regeneração natural, com isso, a cada queimada dentro da UC, o pasto surge com maior robustez e diante da impossibilidade do uso de defensivos agrícolas para o controle de seu crescimento, esta classe apresenta grande quantidade de biomassa, uma vez que seu manejo é feito quase que exclusivamente de maneira manual. 
Há que se destacar as recentes queimadas dentro da área da UC nos anos de 2014 e 2016, essas afetaram principalmente as porções central e sul do parque, perfazendo uma área de mais de 3000 ha. A seguir a Figura 4 expõe, por meio de um gráfico, as áreas das classes de uso do solo da $\mathrm{UC}$.

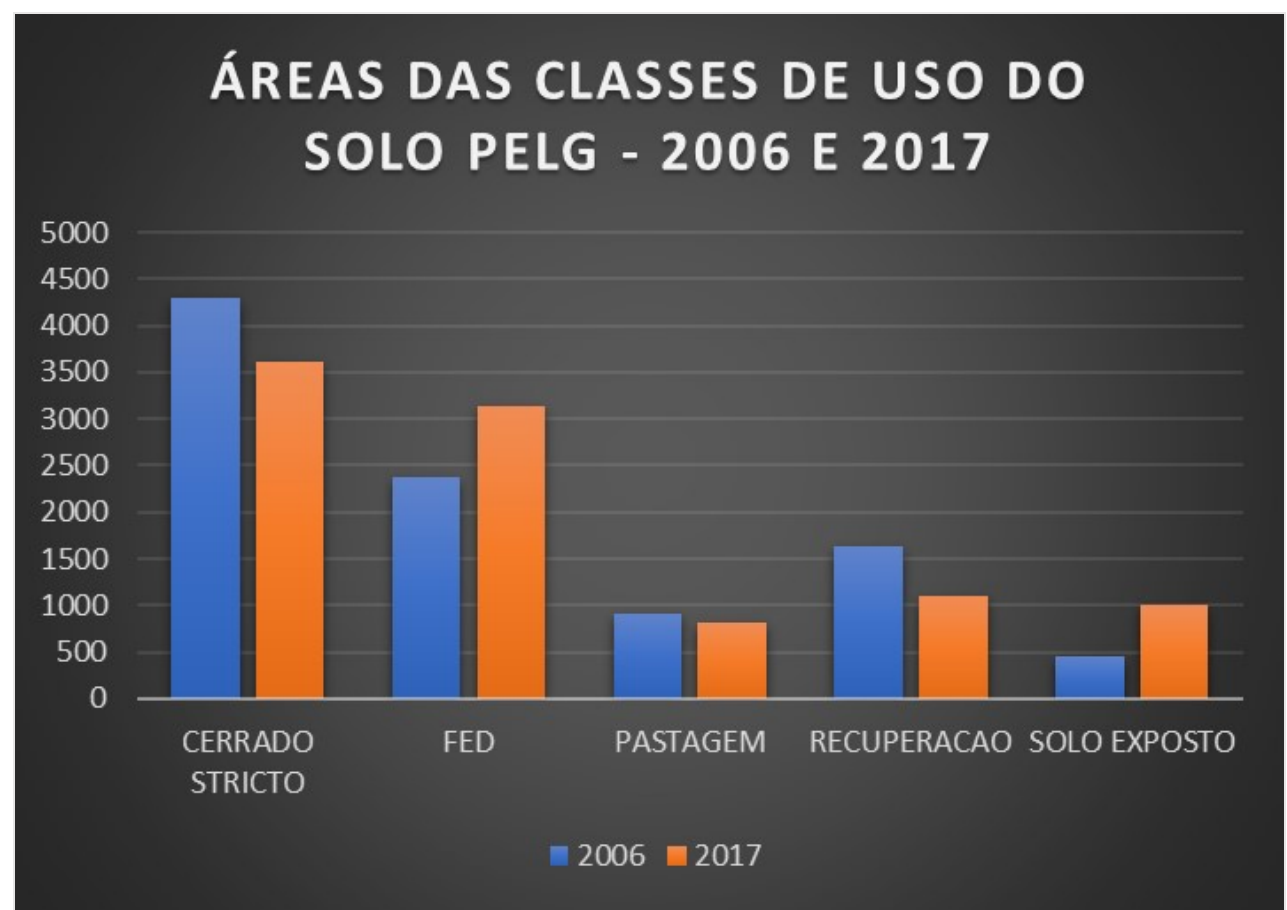

Figura 4 - Gráfico de áreas das classes de uso do solo no Parque Estadual da Lapa Grande. Fonte: Renato Ferreira, 2019.

Mediante a ilustração do gráfico de áreas, é possível compreender a dinâmica de uso do solo ao longo da primeira década de criação do Parque Estadual da Lapa Grande, houve redução nas áreas de Cerrado, pastagem e nas áreas em recuperação e um acréscimo das classes de Floresta Estacional e solo exposto.

As áreas de Cerrado sofreram redução principalmente pela ocorrência de incêndios na UC nos últimos anos, a ocorrência desses foram quase que anuais, e esse fato colabora diretamente com o aumento das áreas de solo exposto (principalmente na porção sul da UC) e posteriormente com as áreas de pastagem, uma vez que após as queimadas, o pasto se desenvolve de forma mais rápida, de comparada as áreas de vegetação nativa.

Contudo, houve o aumento significativo das áreas cobertas por FED, principalmente por essas áreas situarem-se, quase que exclusivamente isoladas nos afloramentos e as matas ciliares nos fundos de vale, que, pelo fato de não sofrerem mais pressão antrópica pelo uso de suas áreas, desenvolveram-se de maneira contínua ao longo dos anos. Já as áreas que estavam em recuperação, foram substituídas pelo Cerrado na porção oeste da UC de maneira maciça, porém, na porção noroeste houve praticamente a manutenção dessas áreas, acompanhadas de solo exposto. 


\section{CONCLUSÃO}

Com o desenvolvimento das geotecnologias, as geociências se beneficiaram de excelentes produtos como softwares e imagens de satélites, além de metodologia confiável para realizar análises ambientais de maneira eficaz e de baixo custo, o que se torna extremamente atrativo para órgãos e pesquisadores do viés ambiental.

Focar atenções e esforços para o manejo de áreas protegidas, é algo essencial para que estes espaços, legalmente instituídos, possam cumprir com seus objetivos de criação, que, no caso da Unidade de Conservação estudada, tem papel fundamental na disponibilização de recurso hídrico para abastecimento da população na cidade de Montes Claros.

Por meio deste trabalho, pode-se concluir que o Parque Estadual da Lapa Grande apresenta 69,83 \% de sua área total com vegetação nativa de Cerrado Stricto Sensu e Floresta Estacional Decidual, valor que corresponde a 6747,58 ha juntamente aos 1819,54 ha de áreas antropizadas, valor que representa $18,83 \%$ e 1095,38 ha que estão em processo de regeneração, correspondendo a 11,34\%. Apesar das dificuldades encontradas na gestão, a UC tem trabalhado na tentativa da redução de áreas antropizadas.

Por fim, é necessário que haja monitoramento contínuo de áreas prioritárias à preservação ambiental, principalmente as antropizadas, a fim de reduzi-las. Uma possível estratégia para resolução de problemas dentro das unidades de conservação são as parcerias público-privadas.

\section{REFERÊNCIAS}

ABREU, K. M. P.; COUTINHO, L. M. Sensoriamento remoto aplicado ao estudo da vegetação com ênfase em índice de vegetação e métricas da paisagem. Vértices, Campos dos Goytacazes, v. 16, n. 1, p. 173-198, 2014.

ALKMIM, F. F.; MARTINS-NETO, M. A. A bacia intracratônica do São Francisco: arcabouço estrutural e cenários evolutivos. In: PINTO, C. P., MARTINS-Neto, M.A. (Eds). Bacia do São Francisco, Geologia e Recursos Naturais. Belo Horizonte: SBG, 2001. p. 9-30.

BARBOSA. V. V.; ASSIS, E. G.; SARMENTO, R. L.; SILVA, C. A.; SILVA, S. X. Resultados do Diagnostico Espeleológico do Parque Estadual da Lapa Grande-Montes Claros.MG. In: CONGRESSO BRASILEIRO DE ESPELEOLOGIA. 33., 2015, Eldorado. Anais... Eldorado, 2015. p. 433-444.

BRASIL. Lei 9.985 de 18 de julho de 2000. Regulamenta o art. 225, § 1O, Incisos I, II, III E VII da Constituição Federal, institui o Sistema Nacional de Unidades de Conservação da Natureza e das Outras providencias. Disponível em: http://www.planalto.gov.br/ccivil_03/leis/19985.htm. Acesso em: 11 mai. 2018.

BRITO, J. L. S.; PRUDENTE, T. D. Mapeamento do Uso da Terra e Cobertura vegetal do Município de Uberlândia-MG, Utilizando Imagens CCD/CBERS 2. Caminhos de Geografia, Uberlândia, v. 13, n. 15, p. 144-153, 2005. 
CARNEIRO, M. F. B. Região Norte de Minas: Caracterização Geográfica e a Organização Espacial - Breves Considerações. Revista Cerrados, Montes Claros, v. 1, n. 1, p. 91-105, 2003.

CORRÊA, R. S.; MELO, B. F. Ecologia da revegetação em áreas escavadas. In: Corrêa, R. S.; MELO, B. F. Ecologia e recuperação de áreas degradadas no Cerrado. Brasília: Paralelo 15,1998. p. 6599.

HOFFMANN. P. P. Caracterização de Fragmentos de Floresta Estacional decidual do Parque Estadual da Lapa Grande, Montes Claros, MG. 2013. 78 f. Dissertação (Mestrado em Ciências Agrárias) - Instituto de Ciências Agrárias, Universidade Federal de Minas Gerais, Montes Claros, 2013.

INSTITUTO ESTADUAL DE FLORESTAS (IEF). Estudo Técnico para Ampliação dos Limites do Parque Estadual da Lapa Grande, Município de Montes Claros, MG. 65 p. Disponível em: http://www.ief.mg.gov.br/instituicao/281?task=view. Acesso em: 20 de jun. de 2018.

INSTITUTO NACIONAL DE PESQUISAS ESPACIAIS (INPE). Características do Satélite CBERS. Disponível em: www.inpe.com.br. Acesso em: 1 ago. 2018.

MINAS GERAIS. Decreto $n^{\circ} 44.204$ de 10 de janeiro de 2006. Cria o Parque Estadual da Lapa Grande no Município de Montes Claros. Disponível em: http:www.siam.mg.gov.br/sla /download.pdf?idnorma=5310. Acesso em: 18 ago. 2018.

MINAS GERAIS. Decreto 46.692 de 29 de dezembro de 2014. Amplia a Área do parque estadual da Lapa Grande no Município de Montes Claros, e Declara a Área de Ampliação como de Utilidade Pública para Fins de desapropriação.

MIRANDA. W. A. Caracterização Física da Microbacia do Córrego dos Bois no Parque Estadual da lapa Grande-Montes Claros/MG. 2008. 40f . Monografia (Trabalho de Graduação em Recursos Hídricos e Ambientais) - Instituto de Ciências Agrarias, Universidade Federal de Minas Gerais, Montes Claros, 2008.

MINISTÉRIO DO MEIO AMBIENTE (MMA). Avaliação e Identificação de Áreas Prioritárias para a Conservação, Utilização Sustentável e repartição dos Benefícios da Biodiversidade dos Biomas Brasileiros. MMA/SBF. BRASÍLIA. 2002. Disponível em: https://www.mma.gov.br/ estruturas/chm/_arquivos/biodivbr.pdf. Acesso em: 20 jun. 2018.

NERY, C. V. M.; MOREIRA, A. A.; FERNANDES, F. H. S. Análise do Comportamento Espectral da Floresta Estacional Decidual no Parque Estadual da Lapa Grande. Revista Brasileira de Geografia Física, Recife, v. 7, n. 2, p. 413-433, 2014.

PILÓ, L. B. Caracterização regional do Vale do Rio Peruaçu. O Cárste, Belo Horizonte, v. 9, n. 2, p. 22-29, 1997.

RATTER, J. A.; RIBEIRO, J. F. Biodiversity of the Flora of the Cerrado. In: SIMPÓSIO SOBRE CERRADO. 1996, Brasilía. Anais... Brasília: EMBRAPA, 1996. p. 3-5.

RIBEIRO, J. F.; WALTER, B. M. T. Fitofisionomias do Bioma Cerrado. In: SANO, S. M.; ALMEIDA S. P. (Eds.). Cerrado Ambiente e Flora. Planaltina. Embrapa, 1998. cap. 3 p. 87-166.

ROSA, R. Introdução ao Sensoriamento Remoto. 5. ed. Uberlândia: EDUFU, 200. 228p. 
SANTIAGO, A. R; PEREIRA. A. Imagens do sensor CCD/CBERS-2 como subsídio na distinção entre fitofisionomias florestais, savânicas e campestres do bioma Cerrado. In: SIMPÓSIO BRASILEIRO DE SENSORIAMENTO REMOTO. 14., 2009, Natal. Anais... Natal: INPE, 2009. p. 25-30.

STEFANES. M.; FILHO, A. C. P. Contribuições ao uso do Sensor CCD/CBERS-2 para a Caracterização da Cobertura do Solo: Um estudo de caso no Cerrado. REA - Revista de Estudos Ambientais, Blumenau, v. 11, n. 2, p. 71-87, 2009.

TRAVASSOS, L. E. P.; KOHLER, H. C. Historical and geomorphological characterisation of a Brazilian karst region. Acta Carsologica, Postojna, v. 38, n. 2/3, p. 277-291, 2009.

TRAVASSOS, L. E. P.; OLIVEIRA, R. I. C. Tufa deposits in the karst region of Montes Claros, Minas Gerais, Brazil. Acta Carsologica, Postojna, v. 45, p. 85-96, 2016.

VELOSO, A. R.; NERY, C. V. M. Geoprocessamento Aplicado à Caracterização do Parque estadual da lapa Grande em Montes Claros/MG. In: SIMPÓSIO BRASILSEIRO DE SENSORIAMENTO REMOTO. 15., 2011. Curitiba. Anais... Curitiba: INPE, 2011. p. 3711. 